\title{
Bone marrow-derived cells contribute to cell turnover in aging murine hearts
}

\author{
SEBASTIAN SZARDIEN ${ }^{1,2}$, HOLGER M. NEF $^{1-3}$, CHRISTIAN TROIDL $^{2}$, MATTHIAS WILLMER $^{1,2}$, \\ SANDRA VOSS ${ }^{2}$, CHRISTOPH LIEBETRAU ${ }^{1,3}$, JEDRZEJ HOFFMANN $^{1,2}$, ANDREAS ROLF $^{1,3}$, \\ JOHANNES RIXE ${ }^{1,3}$, ALBRECHT ELSÄSSER ${ }^{4}$, CHRISTIAN W. HAMM ${ }^{1,3}$ and HELGE MÖLLMANN ${ }^{1-3}$ \\ ${ }^{1}$ Department of Cardiology, Kerckhoff Heart Center; ${ }^{2}$ Experimental Cardiology, Franz-Groedel-Institute, \\ Kerckhoff Heart Center, D-61231 Bad Nauheim; ${ }^{3}$ Department of Cardiology, Medical Clinic I, University of \\ Giessen, D-39392 Giessen; ${ }^{4}$ Department of Cardiology, Klinikum Oldenburg, D-26121 Oldenburg, Germany
}

Received February 10, 2012; Accepted March 12, 2012

DOI: 10.3892/ijmm.2012.995

\begin{abstract}
The paradigm that cardiac myocytes are nonproliferating, terminally differentiated cells was recently challenged by studies reporting the ability of bone marrowderived cells (BMCs) to differentiate into cardiomyocytes after myocardial damage. However, little knowledge exists about the role of BMCs in the heart during physiological aging. Twelve-week-old mice $(n=36)$ were sublethally irradiated and bone marrow from littermates transgenic for enhanced green fluorescent protein (eGFP) was transplanted. After 4 weeks, 18 mice were sacrificed at the age of 4 months and served as controls (group A); the remaining mice were sacrificed at the age of 18 months (group B). Group A did not exhibit a significant number of $\mathrm{eGFP}^{+}$cells, whereas $9.4 \pm 2.8 \mathrm{eGFP}^{+}$cells $/ \mathrm{mm}^{2}$ was documented in group B. In total, only five $\mathrm{eGFP}^{+}$cardiomyocytes were detected in 20 examined hearts, excluding a functional role of BM differentiation in cardiomyocytes. Similarly, a relevant differentiation of BMCs in endothelial or smooth muscle cells was excluded. In contrast, numerous BM-derived fibroblasts and myofibroblasts were observed in group B, but none were detected in group A. The present study demonstrates that BMCs transdifferentiate into fibroblasts and myofibroblasts in the aging murine myocardium, suggesting their contribution to the preservation of the structural integrity of the myocardium, while they do not account for regenerative processes of the heart.
\end{abstract}

\section{Introduction}

Acute myocardial infarction (AMI) remains a major cause of chronic heart failure (HF) due to a loss of myocardial tissue.

Correspondence to: Dr Helge Möllmann, Kerckhoff Heart and Thorax Center, Benekestrasse 2-8, D-61231 Bad Nauheim, Germany E-mail: h.moellmann@kerckhoff-fgi.de

Key words: bone marrow-derived cells, stem cells, transdifferentiation, aging
Although AMI has been postulated to lead to an irrecoverable loss of cardiomyocytes, bone marrow-derived cells (BMCs) might be able to differentiate into cardiomyocytes after AMI. Several experimental studies have confirmed this cardiomyocytogenic capability of BMCs (1-3), whereas others have excluded the differentiation of BMCs in cardiomyocytes (4-8). Clinical trials have demonstrated beneficial effects of BMC treatment (9-11) after AMI with improved functional parameters (9-11) or a complete absence of effects (12). A recent meta-analysis brought the therapeutic impact of BMCs into question (13). Given these controversial experimental and clinical results, the differential potential of BMCs has been critically challenged and the (patho-)physiological relevance of BMCs in the repair of myocardial damage remains unclear. In order to gain a better understanding of the role of BMCs during pathophysiological processes, improving our knowledge of the physiological role of BMCs in the myocardium is indispensible. Thus, we examined the role of BMCs in the physiological aging processes of the heart. For this purpose, we used a mouse model in which the original bone marrow was replaced by an enhanced green fluorescent protein (eGFP)-marked stem cell pool. These labeled cells offer a possibility of clearly identifying the fate and behavior of potentially differentiated BMC offspring.

\section{Materials and methods}

Bone marrow transplantation and transgenic mice. Bone marrow transplantation (BMTx) was performed according to a previously described protocol (6). Briefly, C57BL/6TgN(ACTbEGFP)1Osb transgenic mice (Jackson Laboratory, Bar Harbor, ME, USA) served as bone marrow donors. In this transgenic line, all cells, with the exception of erythrocytes and hair follicle cells, express eGFP and appear green in the presence of excitation wavelengths (14). A total of 36 mice were transplanted. The success of BMTx was monitored by flow cytometric analysis (FACSCalibur, BD Biosciences, Germany).

In 18 mice, hearts were excised at the age of 4 months to serve as the young control group (group A). To investigate the aging myocardium, 18 mice were euthanized at the age of 18 months (group B). 
All investigations conformed to the Guide for the Care and Use of Laboratory Animals published by the US National Institutes of Health (NIH publication no. 85-23, revised 1996) and were approved by the appropriate authorities (Regierungspräsidium Darmstadt, Hessen, Germany).

Perfusion fixation and tissue sampling. The mice were euthanized by cervical dislocation, the thoracic aorta was cannulated, and the hearts were retrograde gravity-perfused at a mean pressure of $100 \mathrm{mmHg}$ with PBS buffer containing $0.1 \%$ adenosine (Fluka, Germany) and $0.05 \%$ bovine serum albumin (Sigma, Germany) for $3 \mathrm{~min}$, followed by fixative (3\% buffered paraformaldehyde solution) for $4 \mathrm{~min}$. Afterwards, the hearts were quickly excised and the tissue cryopreserved in Tissue-Tek OCT Compound (Sakura, Japan) at $-80^{\circ} \mathrm{C}$ until sectioning.

Histological analysis. Serial cryosections of the heart were obtained and 20 representative slices of the whole myocardium were analyzed. Immunostaining was performed on 6- $\mu \mathrm{m}$ cryosections. To assess the incorporation of BM-derived cells into the myocardium, the number of $\mathrm{eGFP}^{+}$cells in all cryosections was determined. Sections of spleen served as positive controls. An anti-eGFP antibody (Abcam, USA) was used to exclude autofluorescent effects. Staining procedures and picture acquisition were performed as previously described (15). All sections were incubated for $2 \mathrm{~h}$ at room temperature. Incubation with the first antibody was followed by treatment with biotinylated secondary antibody when indirectly labeled antibodies were used. The directly labeled antibodies were conjugated to $\mathrm{Cy} 3$. The last incubation was carried out with streptavidin-Cy2 (Rockland Immunochemicals, Inc., USA). Nuclei were stained with DRAQ-5 (Alexis, USA). Omission of the primary antibody served as a negative control. Pictures were captured with a Leica TCS SP laser scanning confocal microscope (Leica, Germany) equipped with appropriate filter blocks using a Silicon Graphics Octane workstation (Silicon Graphics, USA) and three-dimensional multichannel image processing software (Bitplane, Germany).

Flow cytometric analysis. The efficacy of BMTx was determined by fluorescence-based flow cytometry (FCM) of eGFP expression in peripheral blood leukocyte subpopulations. Briefly, aliquots of peripheral blood were stained with a panel of APC-conjugated monoclonal antibodies against CD3, CD4, CD8, CD11b, CD19, and F4/80. Following erythrocyte lysis and washing steps, acquisition was performed on a BD FACS Calibur flow cytometer (BD Biosciences, Germany). Data were analyzed using the CellQuest Software (BD Biosciences).

For tissue analysis, hearts were minced and digested in ADS buffer $(0.11 \mathrm{M} \mathrm{NaCl}, 5 \mathrm{mM} \mathrm{KCl}, 5 \mathrm{mM}$ dextrose, $0.8 \mathrm{mM}$ $\mathrm{MgSO}_{4}, 12.5 \mathrm{mM} \mathrm{NaH}_{2} \mathrm{PO}_{4}, 20 \mathrm{mM}$ HEPES) containing $1 \mathrm{mg} /$ $\mathrm{ml}$ collagenase IV and $0.5 \mathrm{mg} / \mathrm{ml}$ hyaluronidase. The resulting cell suspension was filtered through a $70 \mu \mathrm{m}$ cell strainer (BD Biosciences) and washed twice in $\mathrm{PBS} / 2 \%$ fetal calf serum prior to FCM (EPICS Altra, Beckman Coulter).

\section{Results}

Bone marrow transplantation. The efficacy of BMTx was assessed by FACS analysis of the peripheral blood at different
A
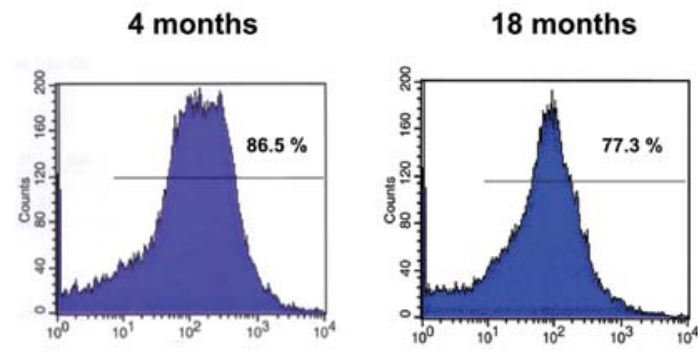

B
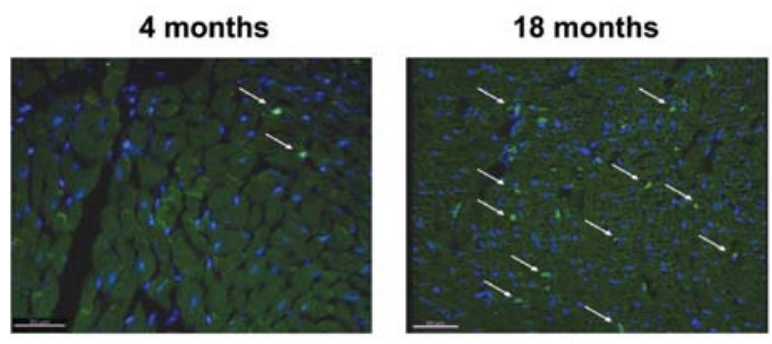

Figure 1. Successful replacement of the original stem cell population. (A) FACS analysis of serum samples. eGFP was expressed in $86.6 \pm 5.1 \%$ of all leukocytes in group A and $77.3 \pm 4.9 \%$ in group B. (B) Representative immunohistochemistry of myocardial sections. Arrows indicate $\mathrm{eGFP}^{+}$cells (green). Nuclei were counterstained with DAPI (blue). In total, less than one $\mathrm{eGFP}^{+}$cell $/ \mathrm{mm}^{2}$ was observed in hearts of young mice, whereas $9.3 \pm 3.3$ myocardial cells $/ \mathrm{mm}^{2}$ were $\mathrm{eGFP}^{+}$in hearts from old mice.

time points after transplantation. Fluorescence intensity showed that $86.5 \pm 5.3 \%$ of all nucleated cells in group A and $77.3 \pm 4.9 \%$ in group B expressed eGFP after BMTx, indicating successful replacement of the original stem-cell population (Fig. 1A). In addition, the proportional leukocyte subpopulations were compared between transplanted and non-transplanted mice using flow cytometry. No significant differences were found between groups, indicating that the white blood cell counts were within the physiological range at the time of surgery (data not shown).

Quantification and phenotype of e $G F P^{+}$cells. Four weeks after BMTx, group A mice were euthanized. Immunohistochemical staining of the myocardium revealed only a small number of $\mathrm{eGFP}^{+}$cells, which were unexceptional leukocytes. In total, $<1 \mathrm{eGFP}^{+}$cells $/ \mathrm{mm}^{2}$ was observed in myocardium samples from group A. In contrast, $9.4 \pm 2.8 \mathrm{eGFP}^{+}$cells $/ \mathrm{mm}^{2}$ were counted in group B samples (Fig. 1B). For additional quantification, hearts were digested and isolated cells analyzed for eGFP by flow cytometry. This quantification documented $0.25 \pm 0.03 \% \mathrm{eGFP}^{+}$cells in group A and $4.2 \pm 1.2 \%$ in group B.

In order to investigate the differentiation of BM-derived cells within the myocardium, cryosections were co-stained with cell type-specific markers. Most of the leukocytes were $\mathrm{eGFP}^{+}$as demonstrated by positive immunohistochemical staining with the pan-leukocyte marker CD45 (Fig. 2A). In contrast to group A, a considerable number of $\mathrm{eGFP}^{+}$cells did not positively stain for CD45 in group B, revealing transdifferentiation into a non-inflammatory cell type.

Cardiomyocytes were characterized by anti-titin staining. We examined 10 hearts per group, detecting only five cardiomyocytes that were $\mathrm{eGFP}^{+}$(group $\mathrm{A} n=3$, group $\mathrm{B} n=2$; Fig. 2B). Immunohistochemicl staining for vimentin showed that 
A

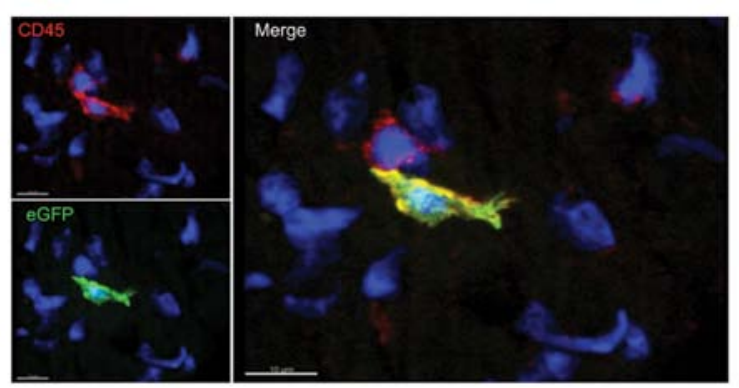

B

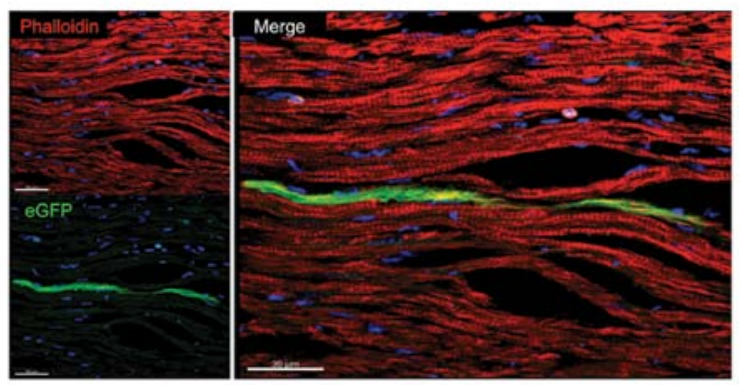

Figure 2. Differentiation of BMCs. (A) Immunohistochemical co-localization of pan-leukocyte marker CD45 (red) and eGFP (green). Nuclei were counterstained with DAPI (blue). Most leukocytes were eGFP'. (B) Detection of transdifferentiated cardiomyocytes by co-staining for phalloidin (red) and eGFP (green). Nuclei were counterstained with DAPI (blue). Only scattered $\mathrm{eGFP}^{+}$cardiomyocytes were observed.

A
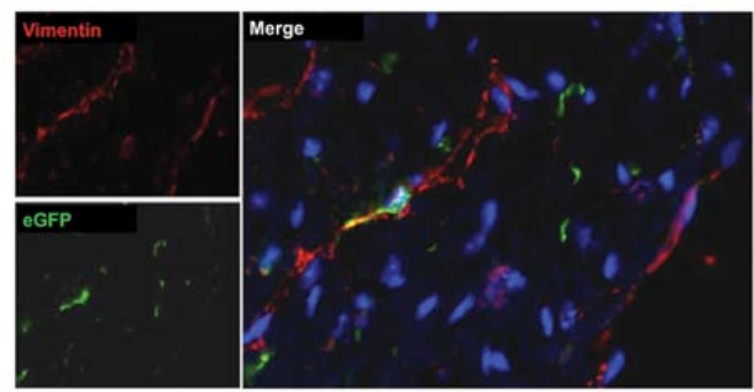

B

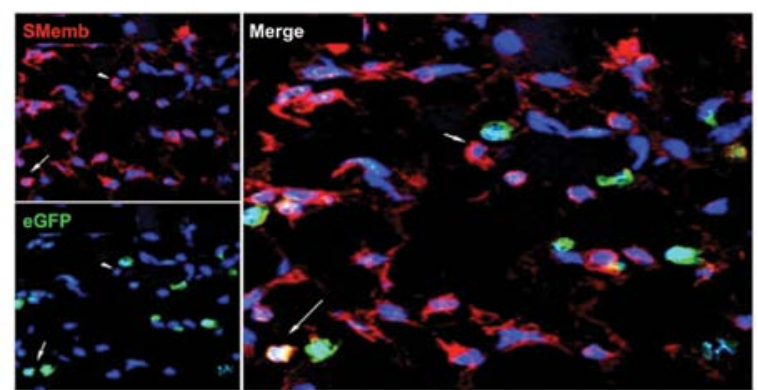

Figure 3. Differentiation of BMCs. (A) Detection of BMC-differentiated fibroblasts by co-staining for vimentin (red) and eGFP (green). Nuclei were counterstained with DAPI (blue). A substantial number of fibroblasts showed clear co-localization with eGFP. (B) Detection of BMC-derived myofibroblasts by co-staining for the specific myofibroblast marker SMemb (red) and eGFP (green). Nuclei were counterstained with DAPI (blue). Arrows indicate $\mathrm{eGFP}^{+}$myofibroblasts, indicating their BMC origin.

some cells co-expressed this fibroblast marker with eGFP, indicating a BM-derived origin in group B (Fig. 3A). To detect myofibroblasts, we used the specific marker SMemb. A considerable number of myofibroblasts were $\mathrm{eGFP}^{+}$, mainly in
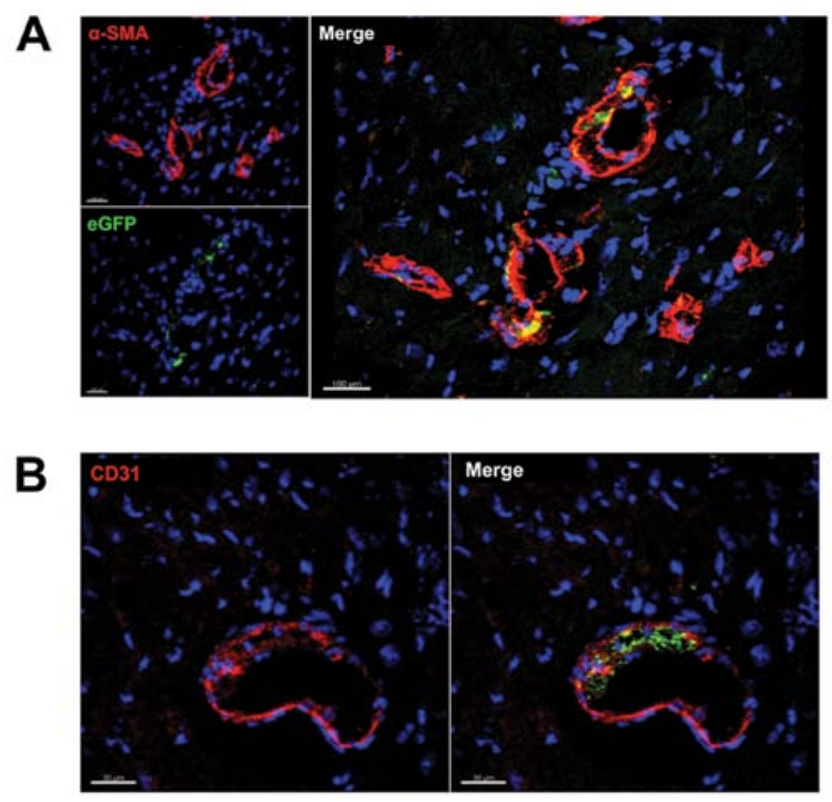

Figure 4. Differentiated $\mathrm{eGFP}^{+}$smooth muscle cells were mainly found in smaller vessels and capillaries. (A) Co-staining for eGFP (green) and $\alpha$-smooth muscle actin ( $\alpha$-SMA, red). Nuclei were counterstained with DAPI (blue). (B) Co-staining for the endothelial cell marker CD31 (red) and eGFP (green). Nuclei were counterstained with DAPI (blue).

group B (Fig. 3B). The occasional $\mathrm{eGFP}^{+}$vascular smooth muscle cells were found primarily in the walls of smaller vessels (Fig. 4A). We also detected bone marrow-derived endothelial cells, which were represented by positive co-staining for eGFP and the endothelial cell marker CD31. These cells were also found primarily in small vessels and capillaries (Fig. 4B). However, the vast majority of $\mathrm{CD} 31^{+}$cells were negative for eGFP.

\section{Discussion}

The adult mammalian heart has long been considered a terminally differentiated, postmitotic organ. However, this dogma has been challenged as the role of BMCs in cardiac repair has been extensively investigated, driven by the goal of developing novel therapies aimed at regenerating the damaged myocardium. The bone marrow comprises a wide variety of stem cells, which are able not only to generate blood cells, but to differentiate into other cell types, including liver cells, neurons, skeletal muscle and endothelial cells (16). During physiological cardiac aging, the heart undergoes several structural and morphological changes, including a substantial increase in interstitial and perivascular fibrosis (17), a progressive loss of cardiomyocytes due to necrosis and apoptosis, hypertrophy of the remaining cardiomyocytes and an increase in the number of cardiac fibroblasts (18). These changes can be designated as 'age-associated cardiomyopathy' (19).

In this study, we demonstrated that during the lifespan of mice, $4 \%$ of cells within the myocardium are recruited from the bone marrow. These BMCs differentiated into tissueresident leukocytes or transdifferentiated into fibroblasts and myofibroblasts. Differentiation into smooth muscle cells and endothelial cells was rarely observed. In addition, only 
a negligibly small number of eGFP ${ }^{+}$cardiomyocytes was detected, indicating that BMC differentiation into these cell types does not contribute to the regenerative processes of the myocardium during aging. These findings are in agreement with data published by Daniel et al (20), who demonstrated that the differentiation of BMCs into smooth muscle cell or endothelial cell lineages is an extremely rare event. The failure of BMCs to transdifferentiate into cardiomyocytes has been clearly shown in our previous work (6) and by that of several other authors $(4,5,8)$.

In contrast, we found a remarkable number of fibroblasts and myofibroblasts of BMC origin. An increased number of cardiac fibroblasts and myofibroblasts in the aging heart has been described $(18,21)$, though several authors found a blunted capacity of fibroblast proliferation during physiological aging $(22,23)$. Given this discrepancy, the origin of these fibroblasts has remained controversial; the traditional view is that activated myofibroblasts are derived from resident fibroblasts through proliferation and activation. However, tracking the proliferating cell populations localized proliferating fibroblast-like cells in the surrounding blood vessels, indicating that these fibroblasts may be recruited by circulating progenitor cells $(24,25)$. This suggestion is in accordance with data demonstrating BMC differentiation in different cardiovascular pathologies $(6,26,27)$. However, the role of BM-derived progenitor cells in the aging heart was unclear. For the first time, our study demonstrates substantial recruitment of BMCs during physiological cardiac aging and relevant differentiation of BMCs into fibroblasts and myofibroblasts. The increased number of BM-derived fibroblasts and myofibroblasts found in our setting may be due to the aging heart having a reduced capacity for fibroblast and myofibroblast formation $(23,28)$. In this context, the increased homing and transdifferentiation of BMCs can be considered a compensatory mechanism for the progressive loss of different cell types in the aging heart.

This awareness might be therapeutically relevant because the age-related increase in post-AMI mortality is at least partially caused by an impaired response of senescent fibroblasts to fibrogenic mediators, resulting in unfavorable scar tissue formation and subsequently disturbed myocardial performance (29-31). Therefore, therapeutic approaches that increase the homing and differentiation of BMCs may enhance the reparative potential of the aged heart after myocardial damage.

The design of the present study is descriptive and data were obtained from a rather small sample size. The considerably small percentage of $\mathrm{GFP}^{+}$cells made quantification of the different cell types and statistical analysis impossible. Further experimental studies are required to confirm the hypothesis that BMCs contribute to cell turnover in the heart during physiological cardiac aging. In addition, the data were acquired in mice. Due to obvious different physiological properties (lifespan, cell turnover), the observations made in our study might not fully translate to human physiology. Nevertheless, our data provide new insights into the physiological impact of BMCs.

In conclusion, our study demonstrates that BMCs transdifferentiate into fibroblasts and myofibroblasts in the aging murine myocardium, suggesting their contribution to the preservation of myocardial structural integrity while they do not account for the regenerative processes of the heart.

\section{References}

1. Orlic D, Kajstura J, Chimenti S, Bodine DM, Leri A and Anversa P: Bone marrow stem cells regenerate infarcted myocardium. Pediatr Transplant 7 (Suppl 3): S86-S88, 2003.

2. Jackson KA, Majka SM, Wang H, et al: Regeneration of ischemic cardiac muscle and vascular endothelium by adult stem cells. J Clin Invest 107: 1395-1402, 2001.

3. Orlic D, Kajstura J, Chimenti S, et al: Mobilized bone marrow cells repair the infarcted heart, improving function and survival. Proc Natl Acad Sci USA 98: 10344-10349, 2001.

4. Balsam LB, Wagers AJ, Christensen JL, Kofidis T, Weissman IL and Robbins RC: Haematopoietic stem cells adopt mature haematopoietic fates in ischaemic myocardium. Nature 428: 668-673, 2004.

5. Murry CE, Soonpaa MH, Reinecke H, et al: Haematopoietic stem cells do not transdifferentiate into cardiac myocytes in myocardial infarcts. Nature 428: 664-668, 2004.

6. Mollmann H, Nef HM, Kostin S, et al. Bone marrow-derived cells contribute to infarct remodelling. Cardiovasc Res 71: 661-671, 2006.

7. Nygren JM, Jovinge S, Breitbach M, et al: Bone marrow-derived hematopoietic cells generate cardiomyocytes at a low frequency through cell fusion, but not transdifferentiation. Nat Med 10: 494-501, 2004.

8. Odorfer KI, Walter I, Kleiter M, Sandgren EP and Erben RG: Role of endogenous bone marrow cells in long-term repair mechanisms after myocardial infarction. J Cell Mol Med 12: 2867-2874, 2008.

9. Kuethe F, Figulla HR, Herzau M, et al: Treatment with granulocyte colony-stimulating factor for mobilization of bone marrow cells in patients with acute myocardial infarction. Am Heart J 150: 115, 2005.

10. Assmus B, Schachinger V, Teupe C, et al: Transplantation of Progenitor Cells and Regeneration Enhancement in Acute Myocardial Infarction (TOPCARE-AMI). Circulation 106: 3009-3017, 2002.

11. Schachinger V, Erbs S, Elsasser A, et al: Intracoronary bone marrow-derived progenitor cells in acute myocardial infarction. N Engl J Med 355: 1210-1221, 2006.

12. Schaefer A, Meyer GP, Fuchs M, et al: Impact of intracoronary bone marrow cell transfer on diastolic function in patients after acute myocardial infarction: results from the BOOST trial. Eur Heart J 27: 929-935, 2006.

13. Martin-Rendon E, Brunskill SJ, Hyde CJ, Stanworth SJ, Mathur A and Watt SM: Autologous bone marrow stem cells to treat acute myocardial infarction: a systematic review. Eur Heart J 29: 1807-1818, 2008.

14. Okabe M,Ikawa M, Kominami K, Nakanishi T and Nishimune $Y$ : 'Green mice' as a source of ubiquitous green cells. FEBS Lett 407: 313-319, 1997.

15. Szardien S, Nef HM, Voss S, et al: Regression of cardiac hypertrophy by granulocyte colony-stimulating factor-stimulated interleukin1 $\beta$ synthesis. Eur Heart J 33: 595-605, 2012.

16. Togel $\mathrm{F}$ and Westenfelder $\mathrm{C}$ : Adult bone marrow-derived stem cells for organ regeneration and repair. Dev Dyn 236: 3321-3331, 2007.

17. Gazoti Debessa CR, Mesiano Maifrino LB and Rodrigues de Souza R: Age related changes of the collagen network of the human heart. Mech Ageing Dev 122: 1049-1058, 2001.

18. Anversa P, Palackal T, Sonnenblick EH, Olivetti G, Meggs LG and Capasso JM: Myocyte cell loss and myocyte cellular hyperplasia in the hypertrophied aging rat heart. Circ Res 67: 871-885, 1990.

19. Treuting PM, Linford NJ, Knoblaugh SE, et al: Reduction of age-associated pathology in old mice by overexpression of catalase in mitochondria. J Gerontol A Biol Sci Med Sci 63: 813-822, 2008.

20. Daniel JM, Bielenberg W, Stieger P, Weinert S, Tillmanns H and Sedding DG: Time-course analysis on the differentiation of bone marrow-derived progenitor cells into smooth muscle cells during neointima formation. Arterioscler Thromb Vasc Biol 30: 1890-1896, 2010.

21. Olivetti G, Melissari M, Capasso JM and Anversa P: Cardiomyopathy of the aging human heart. Myocyte loss and reactive cellular hypertrophy. Circ Res 68: 1560-1568, 1991. 
22. Lindsey ML, Goshorn DK, Squires CE, et al: Age-dependent changes in myocardial matrix metalloproteinase/tissue inhibitor of metalloproteinase profiles and fibroblast function. Cardiovasc Res 66: 410-419, 2005.

23. Wolf FI, Torsello A, Covacci V, et al: Oxidative DNA damage as a marker of aging in WI-38 human fibroblasts. Exp Gerontol 37: 647-656, 2002 .

24. Ljungqvist A and Unge G: The proliferative activity of the myocardial tissue in various forms of experimental cardiac hypertrophy. Acta Pathol Microbiol Scand A 81: 233-240, 1973.

25. Mandache E, Unge G, Appelgren LE and Ljungqvist A: The proliferative activity of the heart tissues in various forms of experimental cardiac hypertrophy studied by electron microscope autoradiography. Virchows Arch B Cell Pathol 12: 112-122, 1973.

26. van Amerongen MJ, Bou-Gharios G, Popa E, et al: Bone marrowderived myofibroblasts contribute functionally to scar formation after myocardial infarction. J Pathol 214: 377-386, 2008.

27. Kania G, Blyszczuk P, Stein S, et al: Heart-infiltrating prominin $-1^{+} / \mathrm{CD} 133^{+}$progenitor cells represent the cellular source of transforming growth factor beta-mediated cardiac fibrosis in experimental autoimmune myocarditis. Circ Res 105 462-470, 2009.
28. Cieslik KA, Trial J and Entman ML: Defective myofibroblast formation from mesenchymal stem cells in the aging murine heart rescue by activation of the AMPK Pathway. Am J Pathol 179: 1792-1806, 2011.

29. Bujak M, Kweon HJ, Chatila K, Li N, Taffet G and Frangogiannis NG: Aging-related defects are associated with adverse cardiac remodeling in a mouse model of reperfused myocardial infarction. J Am Coll Cardiol 51: 1384-1392, 2008.

30. Shivakumar K, Dostal DE, Boheler K, Baker KM and Lakatta EG: Differential response of cardiac fibroblasts from young adult and senescent rats to ANG II. Am J Physiol Heart Circ Physiol 284: H1454-H1459, 2003

31. Ertl $\mathrm{G}$ and Frantz S: Healing after myocardial infarction. Cardiovasc Res 66: 22-32, 2005. 